\title{
Um olhar sobre a autoficção de Caio Fernando Abreu
}

Cristiane Rodrigues de Souza

C ONHECEDOR perspicaz da obra de Caio Fernando Abreu, Nelson Luís Barbosa, no seu trabalho de doutoramento, percebe a importância da realização de um estudo das narrativas do escritor gaúcho, tendo em vista o encontro entre o fazer literário e a experiência de vida do autor. A tese, que tem na autoficção sua chave teórica, transformada em livro, pode agora dialogar com um público mais amplo, por meio do lançamento, em 2019, de Infinitivamente pessoal: a autoficção de Caio Fernando Abreu, edição cuidadosa da editora Alameda.

Por meio de um texto claro, aberto ao leitor não especializado, sem, no entanto, abandonar o rigor acadêmico, o estudioso traz relevantes contribuições para os estudos literários, apontadas já no prefácio da professora Andrea Saad Hossne e no texto da professora Sandra Nitrini presente na quarta capa. Ambos destacam a importante reflexão teórica desenvolvida por Nelson, ao estudar a autoficção, ampliando os debates nessa área, assim como apontam o valor inegável da crítica que o estudioso tece em torno da obra de Caio Fernando Abreu, num livro que se constitui, assim, como referência indispensável aos estudos do escritor.

No livro, o leitor é convidado de maneira sutil pelo pesquisador a conhecer a obra de Caio Fernando Abreu, sentindo-se a abrir livros no momento das primeiras publicações e a flagrar, em jornais, o processo de sua recepção. Da mesma forma, o contato com as questões teóricas é significativo, já que o leitor é levado a percorrer os caminhos que levaram ao surgimento do termo autoficção, por meio da retomada de diferentes estudiosos. $\mathrm{O}$ envolvimento do leitor é possível, porque, no estudo de Nelson, a experiência do pesquisador não é deixada de lado, sendo, pelo contrário, partilhada com o outro, no tom de quem sabe narrar e surpreender quem lê com a própria descoberta acadêmica, como ao inserir pontos de exclamações ao lado de achados - "([...] aparece de turbante!)" (p.54).

$\mathrm{O}$ livro divide-se em três partes. $\mathrm{Na}$ primeira, intitulada "Conhecendo Caio F.", o estudioso é hábil ao conduzir o leitor por um percurso que parte da publicação dos primeiros textos do jovem Caio até momentos posteriores, atento à sua recepção crítica, revelada com base em pesquisa incansável que a flagra em textos encontrados em orelhas de livros, prefácios e matérias de jornais, entre outros. Ao fazer isso, o estudioso também destaca, na crítica, o que ele, de maneira segura, começa a mostrar ao leitor, a saber, a importância da presença da escrita do eu na obra do escritor gaúcho, posicionando-se, no diálogo com outros estudiosos, com voz assertiva, capaz de denunciar equívocos. Tendo em vista que a produção do escritor está intimamente ligada à sua experiência de vida, ainda na primeira parte, Nelson mostra que a obra do escritor não se resume a aspectos autobiográficos, como quer 
acreditar parte da crítica, apesar de ser possível encontrar, na ficção, num paradoxo, elementos da vida do autor, como a homossexualidade, a doença e a aproximação da morte, fatos conhecidos, como afirma o estudioso, por meio da correspondência editada, de entrevistas, crônicas e depoimentos. Partindo desse paradoxo, o ensaísta cria no leitor a necessidade de se deter, com ele, em aspectos teóricos da autobiografia e da autoficção, desenvolvidos na segunda parte do livro.

No cuidadoso estudo sobre autobiografia, Barbosa convida o leitor a acompanhar as reflexões de Philippe Lejeune, mostrando como o estudioso define o gênero a partir do compromisso que se estabelece entre o leitor e o autor, num pacto autobiográfico, oposto ao pacto de ficção, estando o primeiro repousado numa suposta verdade e o segundo na verossimilhança, destacando ainda a existência do homonimato entre o nome do autor, do narrador e do personagem como parte da definição do gênero. Além disso, temos a chance de, ao lado de Barbosa, acompanhar o mea culpa de Lejeune, a partir da releitura que o ensaísta faz da própria obra, em que um imaginado "suspiro enfarado" (p.142) introduz novas considerações sobre a autobiografia, vendo-a finalmente como um texto que se afasta das características do romance. O gesto imaginado naquele que revê a própria trajetória ajuda a compor o tom do estudo de Nelson Barbosa, acompanhado com prazer pelo leitor.

Se, ao voltar seu olhar aos estudos acerca de autobiografia no Brasil, o estudioso percebe que o gênero é pouco mencionado pela crítica, descobre que ela, menos ainda, se detém na autoficção, termo criado por Serge Doubrovsky, de acordo com Barbosa, num desdobramento do conceito de autobiografia estabelecido por Lejeune. Instigado pela complexidade teórica que dá base à compreensão da autobiografia e da autoficção, o pesquisador estuda com cuidado o segundo termo, diferenciando-o do primeiro, estudo importante a ser realizado, num trabalho que procura se deter na obra de Caio Fernando Abreu. Dessa forma, fica claro que as incursões do crítico, portanto, não são gratuitas, pelo contrário, seguem um fio condutor preciso que leva à leitura certeira da obra do escritor.

Assim, ainda na segunda parte de seu livro, o estudioso define autoficção como "um dos modos de tratar uma 'verdade', sem perder o caráter literário da 'escrita do eu'" (p.165). Procurando a origem do termo, ele a encontra em romance de Serge Doubrovsky, publicado em 1977, autor que, de acordo com Isabelle Grell, no texto "Pourquoi Serge Doubrovsky n'a pu éviter le terme d'autofiction" ["Por que Serge Doubrovsky não pôde evitar o termo da autoficção"], citado por Barbosa, entende a autoficção como uma narrativa em que a construção linguística se sobrepõe aos fatos, num domínio da linguagem sobre o vivido (p.175). Além disso, em seu estudo de Doubrovsky, Grell conclui que, na autoficção, o leitor não está do outro lado do pacto, mas é levado não apenas a conferir a "verdade" dos fatos como a participar da narrativa, a partir do reconhecimento da verossimilhança ficcional, assumindo a postura de um leitor de romance que participa do que lê (p.175). Ao definir o termo, em entrevista concedida a Philippe Vilain, como lembra Nelson Barbosa, Doubrovsky afirma que, na autoficção, há a coincidência de 
identidade entre autor, narrador e personagem, num texto em que o autor insere seu próprio nome na narrativa (p.1778), diferenciando-se, assim, de outras elaborações literárias. Essa definição, como lembra Barbosa, foi depois ampliada, nos estudos de Vincent Colonna, ensaísta que, ao lado de Doubrovsky, dá base à pesquisa de Barbosa. Colonna caracteriza a autoficção como o conjunto de elementos que levam à ficcionalização do eu. Para ele, sendo o autor a personagem de sua história, pode ser referido, no entanto, de maneira mais direta ou de forma indireta.

$\mathrm{Na}$ terceira parte de Infinitamente pessoal, após ter se detido em dois momentos da obra de Caio que, de acordo com o estudioso, se configuram como espécies de autobiografias - a novela infanto-juvenil As frangas e o livro de contos Ovelhas negras -, lembrando que o conceito de autoficção não se prende a estruturas fixas de gênero, mas se configura como uma forma de escrita que pode ser encontrada em contos, novelas e romances, Barbosa passa, no sétimo capítulo, a analisar textos de Caio, sob a óptica de Serge Doubrovsky, e, no oitavo, na perspectiva de Vincent Colonna. O leitor, ao acompanhar as análises, é levado pelo texto de Nelson Barbosa a participar do estudo das narrativas, percebendo como são marcadas por momentos importantes da vida do escritor. Entre os diferentes textos estudados está, por exemplo, o conto "Lixo e purpurina", ligado a uma espécie de autoexílio de Caio Fernando Abreu, em Londres, entre 1973 e 1974, escrito, portanto, como demonstra o estudioso, com base na mistura entre realidade e ficção. A dedicatória, por exemplo, elemento paratextual importante em Caio F., como lembra Barbosa, faz referência aos amigos que vivenciaram situações exploradas no conto, Sandra Laporta e Homero Paim Filho. Além disso, ao consultar a correspondência estabelecida pelo escritor no período, em que o pesquisador encontra, em alguns momentos, a semelhança de dicção entre trechos de cartas e do conto, Nelson Barbosa é capaz de identificar, na ficção, eventos da realidade, como a referência ao trabalho como modelo vivo, na Inglaterra, por meio do qual o jovem Caio procurava fugir da penúria.

$\mathrm{Na}$ conclusão de seu trabalho, Nelson Luís Barbosa mostra como, para Caio Fernando Abreu, escrever significa criar novos mundos, não no intuito de abandonar o mundo real, mas, ao contrário, contando com a possibilidade de ampliá-lo, transformando o texto no lugar em que o autor pode buscar, pela experiência, sua "verdade mais íntima" (p.341) e em que leitor consegue, por empatia, também se conhecer em níveis profundos (p.397; 400). Sendo esse um processo próprio de todo texto literário, é interessante notar que Nelson Barbosa demonstra como a autoficção de Caio acaba por intensificá-lo, na medida em que, por meio dela, o leitor vive experiência similar àquela do espectador de teatro que, tendo aceitado a viagem proporcionada pela ficção, vê à sua frente um personagem, mas "ainda assim consegue, como numa segunda ou terceira dimensão, ver também em cena o ator em sua mais concreta humanidade" (p.400).

Assim como vida e ficção se entrelaçam na escrita de Caio, no livro de Nelson Barbosa está, ao lado do rigor da academia, o gesto pessoal do estudioso, percebido, na medida em que ele convida o leitor a acompanhar de perto o 
próprio percurso de pesquisa, fazendo-o ver de maneira bastante significativa a complexidade da obra estudada. Dessa forma, não se escondendo em um texto impessoal, o gesto do ensaísta se revela já numa das epígrafes do livro, ou melhor dizendo, na autoepígrafe que aparece ao lado de trechos de Caio Fernando Abreu e de Hervé Guibert, misturados, na mesma página, às dedicatórias - "Caio, aquele bilhetinho que certa vez comecei a lhe escrever demorou tanto a ser escrito, que acabou resultando neste trabalho. Receba-o, assim, com o carinho de sempre, onde quer que você esteja. Nelson” (p.5). A autoepígrafe anuncia um traço importante do trabalho, a saber, o afeto que permeia a ligação entre o estudioso e a obra de Caio, funcionando ainda como uma espécie de dedicatória. Como afirma Gérard Genette (2009, p.140), em Paratextos editoriais, obra mencionada no trabalho de Nelson, "poder-se-ia imaginar casos em que a epígrafe estaria [...] tão intimamente ligada à dedicatória que ela seria clara e exclusivamente destinada ao dedicatário, mas não conheço nenhum caso". No caso em questão, como na autoepígrafe há uma espécie de homenagem a Caio, percebemos que "a obra [foi] escrita para seu dedicatário” (Genette, 2009, p.118), ou seja, foi redigida também para Caio F. Ela, além disso, sendo também um pequeno bilhete, faz menção ao antigo epitexto particular que, no entanto, se transformou numa longa conversa e depois no próprio livro. Dessa forma, ao ligar, a própria vida ao trabalho do crítico, Nelson entende a crítica como um gesto de amor, reconhecido também na obra de Caio, pronto a admitir, na conversa entre amigos, o leitor, sempre convidado a participar.

\section{Referências}

BARBOSA, N. L. Infinitivamente pessoal: a autoficção de Caio Fernando Abreu, o biógrafo da emoção. São Paulo: Alameda, 2019.

GENETTE, G. Paratextos editoriais. Trad. Álvaro Faleiros. Cotia: Ateliê, 2009.

Cristiane Rodrigues de Souza é doutora em Letras pela Faculdade de Filosofia, Letras e Ciências Humanas da USP, professora adjunta de Literatura na Universidade Federal de Mato Grosso do Sul, instituição em que atua na Graduação e no Programa de Pós-Graduação em Letras.

@ - cris.rodrigues.de.souza@gmail.com / https://orcid.org/0000-0001-7695-0684 ${ }^{\mathrm{I}}$ Universidade Federal de Mato Grosso do Sul, Pioneiros. Mato Grosso do Sul, Brasil.

Recebido em 27.8.2019 e aceito em 23.9.2019 